03

\title{
Электропроводность наножидкостей с металлическими частицами
}

\author{
(c) В.Я. Рудяк ${ }^{1-3}$, А.В. Минаков ${ }^{1,2}$, М.И. Пряжников ${ }^{1,2}$ \\ ${ }^{1}$ Новосибирский государственный архитектурно-строительный университет, \\ Новосибирск, Россия \\ ${ }^{2}$ Сибирский федеральный университет, \\ Красноярск, Россия \\ ${ }^{3}$ Новосибирский государственный университет, \\ Новосибирск, Россия \\ E-mail: valery.rudyak@mail.ru
}

Поступило в Редакцию 31 января 2019 г.

В окончательной редакции 12 февраля 2019 г.

Принято к публикации 12 фревраля 2019 г.

\begin{abstract}
Проведены экспериментальные исследования электропроводности наножидкостей на основе воды и этиленгликоля с частицами меди и алюминия. Параллельно измерена их теплопроводность и исследована реология. Показано, что электропроводность наножидкостей практически линейно растет с увеличением концентрации наночастиц. Электропроводность в отличие от теплопроводности растет с уменьшением размера частиц. С учетом этого сделан вывод, что механизмы электропроводности и теплопроводности наножидкостей существенно различаются.
\end{abstract}

DOI: 10.21883/PJTF.2019.09.47712.17720

Более двадцати лет наножидкости, т.е. дисперсные флюиды с наночастицами, активно изучаются многими десятками исследовательских групп в разных странах мира. Уже сегодня они активно используются в различных приложениях (см., например, работу [1] и цитируемую в ней литературу). При этом оказалось, что теплофизические свойства наножидкостей радикально отличаются от свойств обычных крупнодисперсных жидкостей. К настоящему времени надежно установлено, что коэффициенты переноса наножидкостей зависят не только от концентрации наночастиц, но и от их размера и материала (см. работы [1-9] и цитируемую в них литературу). При этом и коэффициент вязкости, и коэффициент теплопроводности, как правило, существенно превышают соответствующие значения, определяемые классическими теориями [10-12].

Наряду с вязкостью и теплопроводностью для различных приложений весьма важно знать электропроводность наножидкостей. В последние годы появилось значительное число публикаций, где экспериментально изучалась электропроводность наножидкостей с углеродными нанотрубками. Однако известно всего несколько работ, в которых представлены экспериментальные данные по изучению электропроводности наножидкостей с обычными сферическими частицами (см. [13,14] и цитированную там литературу). По этой причине все еще неясно, как электропроводность наножидкостей зависит от размера частиц, как она связана с теплопроводностью и влияет ли на нее реология наножидкости. Экспериментальному ответу на эти вопросы и посвящена настоящая работа.

Рассматривались наножидкости на основе дистиллированной воды и этиленгликоля с частицами меди и алюминия $\left(\mathrm{L}-\mathrm{ALEX} \mathrm{X}^{\mathrm{TM}}\right)$. Средний размер наночастиц меди по данным БЭТ (Брунауэра, Эмметта, Теллера) [15] составлял 56 и $98.8 \mathrm{~nm}$, а наночастиц алюминия $90.7 \mathrm{~nm}$. Массовая концентрация наночастиц $w$ варьировалась от 1.68 до 20\%. Для приготовления наножидкостей использовался стандартный двухшаговый метод. Необходимое количество порошка добавлялось в жидкость, после чего полученная суспензия тщательно механически перемешивалась. Чтобы разрушить конгломераты наночастиц, суспензии подвергались обработке ультразвуковым аппаратом УЗТА-0.4/22-ОМ в течение $20 \mathrm{~min}$. Все представленные в настоящей работе измерения выполнены при температуре $20^{\circ} \mathrm{C}$.

Удельная электропроводность измерялась кондуктометром „АНИОН 7025“. Диапазон измерения удельной электрической проводимости от $10^{-4}$ до $10 \mathrm{~S} / \mathrm{m}$. Точность измерений не ниже $2 \%$. Одновременно измерялись коэффициенты теплопроводности и вязкости наножидкостей. В первом случае применялся метод нагреваемой нити [16], а вязкость измерялась ротационным вискозиметром Brookfield DV2T с использованием шпинделя LV-61. И в том, и в другом случае точность была также не ниже $2 \%$.

Установлено, что во всех случаях удельная электропроводность растет с увеличением концентрации наночастиц. На рис. 1 в качестве примера представлена зависимость удельной относительной электропроводности наножидкости на основе этиленгликоля $(a)$ и воды $(b)$ с частицами алюминия от их массовой концентрации. Здесь $\sigma$ и $\sigma_{0}$ - удельная электропроводность наножидкости и базовой жидкости соответственно. В обоих случаях удельная электропроводность наножидкостей растет с увеличением массовой концентрации частиц. Однако увеличение удельной электропроводности наножидкости на основе этиленгликоля составило всего 23\% 

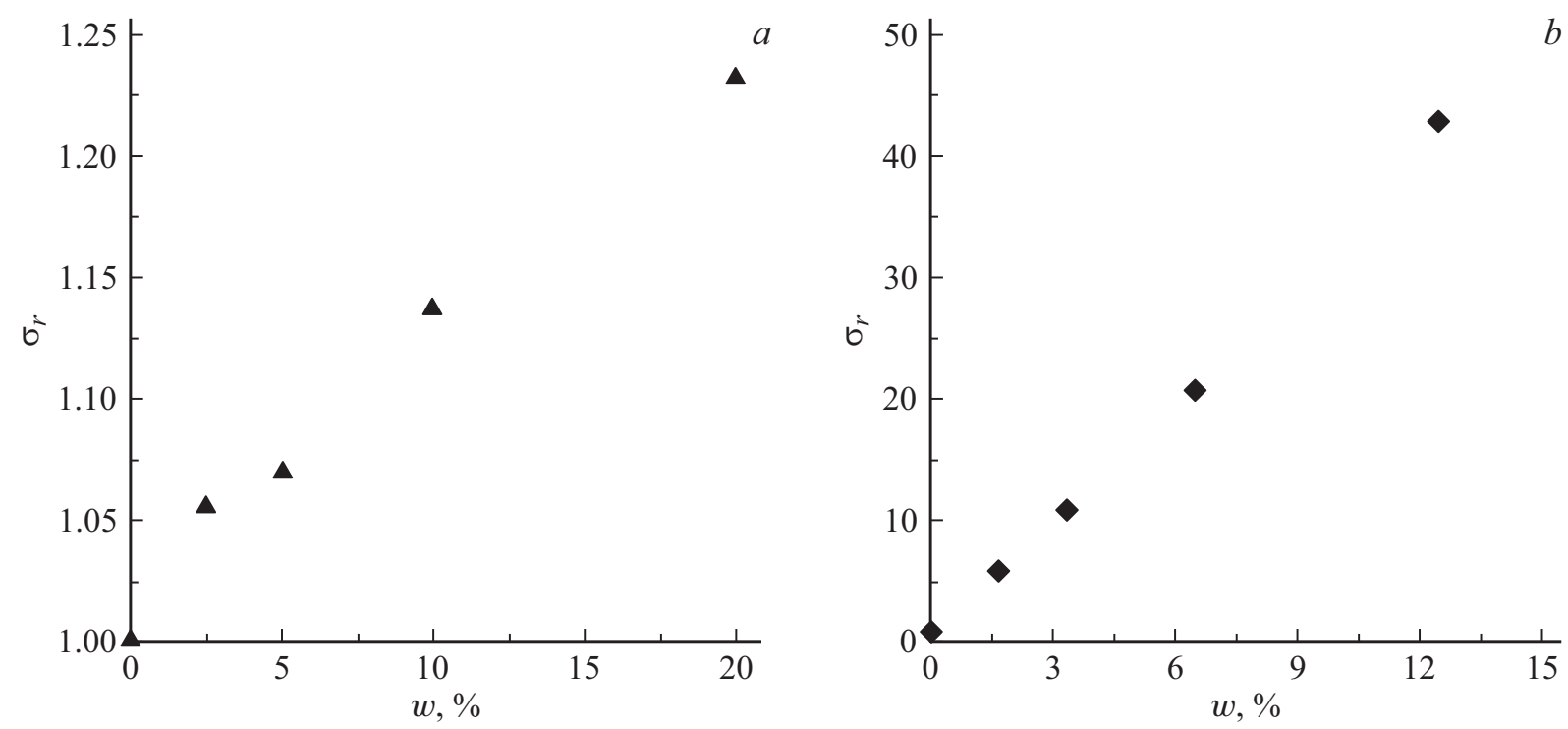

Рис. 1. Зависимость удельной относительной электропроводности наножидкости на основе этиленгликоля $(a)$ и воды $(b)$ с частицами алюминия от их массовой концентрации.
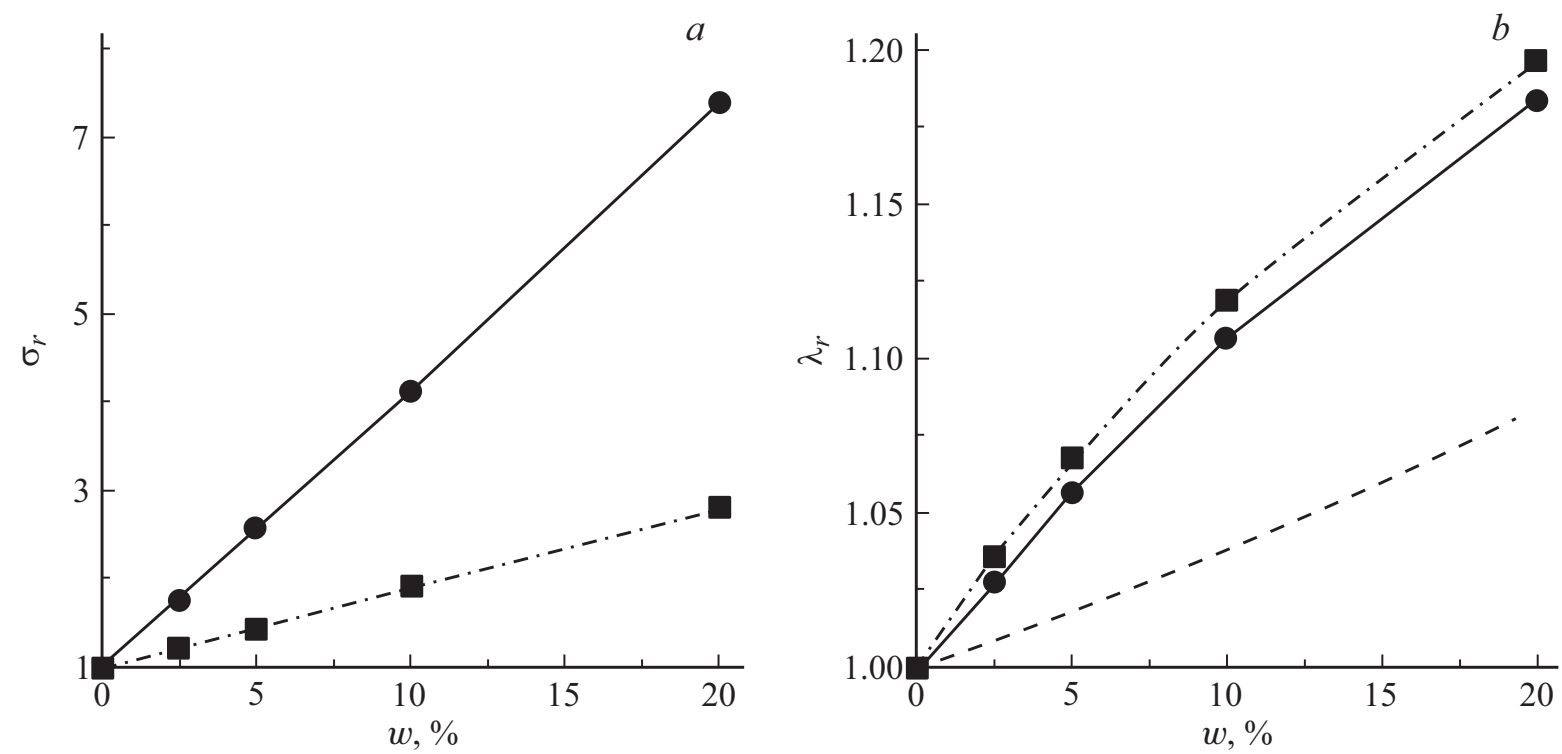

Рис. 2. Зависимость удельной относительной электропроводности $(a)$ и относительного коэффициента теплопроводности $(b)$ наножидкостей на основе этиленгликоля с частицами меди от их массовой концентрации. Пояснение в тексте.

(рис. 1,a). При этом коэффициент удельной электропроводности использованного этиленгликоля равнялся $0.91 \mu \mathrm{S} / \mathrm{cm}$. С другой стороны, удельная электропроводность наножидкости на основе воды увеличилась более чем на два порядка (рис. 1, $b$ ). Коэффициент удельной электропроводности использованной воды составлял $3.1 \mu \mathrm{S} / \mathrm{cm}$. Рост электропроводности наножидкости с увеличением массовой концентрации наночастиц практически линейный: $\sigma_{r}=1+a w$, где $a-$ некоторый коэффициент пропорциональности.

Как уже отмечалось, и вязкость, и теплопроводность наножидкостей существенно зависят от размера наночастиц. Зависимость относительной электропроводности наножидкостей на основе этиленгликоля с частицами меди разного размера от их массовой концентрации представлена на рис. 2, $a$. Здесь кружки соответствуют наножидкости с частицами размером $56 \mathrm{~nm}$, а квадраты - $98.8 \mathrm{~nm}$. Зависимость электропроводности от массовой концентрации частиц в обоих случаях также линейная, причем коэффициент $a$ в приведенной выше формуле для наножидкостей с частицами $\mathrm{Cu}$ размером 56 и $98.8 \mathrm{~nm}$ равен 0.318 и 0.0894 соответственно. Важно отметить, что электропроводность наножидкости с малыми частицами больше, чем для наножидкости с крупными. При массовой концентрации наночастиц меди $20 \%$ это превышение составляет 2.5 раза. 

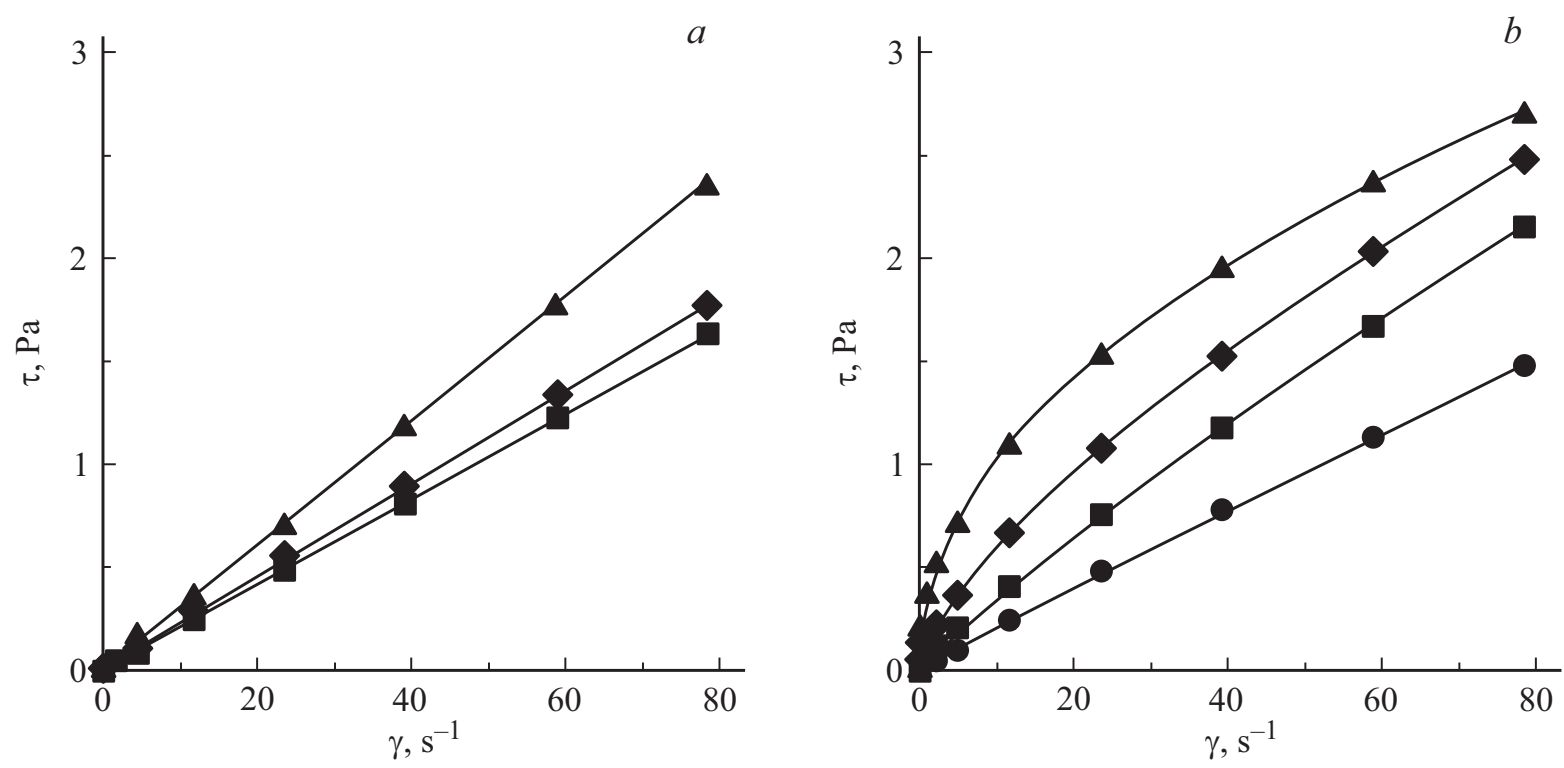

Рис. 3. Зависимость напряжения сдвига наножидкостей на основе этиленгликоля с частицами меди размером $98.8(a)$ и $56 \mathrm{~nm}(b)$ от скорости сдвига. Пояснение в тексте.

Напротив, коэффициент теплопроводности растет с увеличением размера частиц. Его зависимость от концентрации наночастиц для тех же наножидкостей, что и на рис. 2, $a$, представлена на рис. $2, b$ (обозначения те же, что на рис. $2, a)$. Здесь $\lambda_{r}=\lambda / \lambda_{0}\left(\lambda, \lambda_{0}-\right.$ коэффициенты теплопроводности наножидкости и базовой жидкости соответственно), а штриховая линия соответствует данным теории Максвелла [12].

Итак, подводя итог, можно сделать два основных вывода.

Во-первых, добавление металлических наночастиц в базовую, слабо проводящую жидкость существенно увеличивает ее электропроводность. Это соответствует и данным ранее проводившихся измерений на других наножидкостях $[13,14]$. Эффект зависит от электропроводности самих наночастиц. Однако эта зависимость не является линейной. Так, электропроводность меди в 1.58 раза выше, чем у чистого алюминия. Тем не менее приращения электропроводности наножидкостей с частицами меди и алюминия при массовой концентрации $20 \%$ различаются более чем на порядок.

Во-вторых, электропроводность наножидкостей увеличивается с уменьшением размера наночастиц. С другой стороны, теплопроводность наножидкости, напротив, растет с увеличением размера частиц. Таким образом, механизмы электропроводности и теплопроводности наножидкостей существенно различаются.

Механизмы электропроводности наножидкостей с металлическими частицами, конечно, весьма сложны и требуют дальнейшего изучения. Здесь отметим лишь достаточно очевидное. Электропроводность зависит от подвижности наночастиц, и эта подвижность тем выше, чем меньше их размер. Легко получить простую оценку. Подвижность обратно пропорциональна силе сопротив- ления, действующей в жидкости на наночастицу. Для не слишком малых частиц, которые и рассматривались в настоящей работе, эта сила довольно хорошо описывается силой Стокса [17]. Поэтому подвижность наночастиц $l_{n}$ (а следовательно, в значительной степени и удельная электропроводность наножидкостей) определяется соотношением $l_{n} \sim(6 \pi R \mu)^{-1}$, где $\mu-$ коэффициент вязкости базовой жидкости, а $R-$ радиус наночастицы.

Вообще говоря, вода, которая использовалась в качестве базовой жидкости, имела достаточно высокую электропроводность. Это свидетельствует о том, что минеральная часть, состоящая из ионов натрия, кальция, хлора и некоторых других, была довольно значительной. Помимо этого в ней образуются гидроксилы и гидроксонии. Все указанные ионы и обеспечивают электропроводность воды. Легко убедиться, что обусловленная ими составляющая электропроводности также будет обратно пропорциональна действующей на ионы силе сопротивления, и поэтому $l_{i} \sim\left(6 \pi r_{i} \mu\right)^{-1}$, где $r_{i}-$ радиус иона. Строго говоря, следует отметить, что при наличии гидроксония имеет место и квазипротонная проводимость.

Однако все это справедливо лишь для ньютоновских жидкостей. Измерения коэффициента вязкости и реологии наножидкостей показали, что суспензии с наночастицами $\mathrm{Cu}$ размером $98.8 \mathrm{~nm}$ являются ньютоновскими (рис. $3, a$ ) во всем диапазоне рассматриваемых концентраций. На рис. 3 представлена зависимость напряжений сдвига $\tau$ от скорости деформации $\gamma$. Здесь треугольники, ромбы и квадраты отвечают массовым концентрациям 5, 10 и $20 \%$ соответственно. Наножидкость же на основе этиленгликоля при низких концентрациях частиц $\mathrm{Cu}$ размером $56 \mathrm{~nm}$ оказывается ньютоновской (рис. $3, b$ ), а при концентрации 10 и 20\% - неньютоновской, причем 
ее реология хорошо описывается моделью степенной жидкости. На рис. $3, b$ кружки соответствуют массовой концентрации $2.5 \%$.

Наножидкость на основе воды с частицами алюминия при минимальной концентрации частиц $(2.5 \%)$ является ньютоновской, а при больших концентрациях $(5,10$ и $20 \%$ - неньютоновской, причем ее реология хорошо описывается моделью вязкопластической жидкости Хершеля-Балкли. С другой стороны, наножидкости с теми же частицами на основе этиленгликоля оказываются неньютоновскими лишь при максимальной концентрации частиц (20\%). При всех остальных концентрациях $(10,5,2.5 \%)$ они имеют ньютоновскую реологию.

В неньютоновских жидкостях ситуация с подвижностью частиц много сложнее, потому что, во-первых, сила сопротивления, действующая на уединенную частицу, в общем случае теперь нелинейно зависит от ее радиуса (см., например, [18]), а во-вторых, она зависит от скорости сдвига. И при разных скоростях сдвига эффективный коэффициент вязкости среды будет различным. Поэтому в реальных течениях, где скорость сдвига меняется, разной будет и подвижность частиц и ионов.

\section{Финансирование работы}

Работа выполнена при частичной поддержке Российского фонда фундаментальных исследований (гранты № 17-01-00040, 17-58-45023).

\section{Список литературы}

[1] Рудяк В.Я., Минаков А.В. Современные проблемы микрои нанофлюидики. Новосибирск: Наука, 2016. 298 с.

[2] Timofeeva E.V., Smith D.S., Yu W. // Nanotechnology. 2010. V. 21. N 21. P. 215703.

[3] Рудяк В.Я., Краснолуцкий С.Л. // ЖТФ. 2015. Т. 85. В. 6. C. 9-16.

[4] Devendiran D.K., Amirtham V.A. // Renewable Sustainable Energy Rev. 2016. V. 60. P. 21-40.

[5] Das P.K., Islam N., Santra A.K., Ganguly R. // J. Mol. Liq. 2017. V. 237. P. 304-312.

[6] Rudyak V.Ya., Minakov A.V. // Eur. Phys. J. E. 2018. V. 41. N 1. P. 15 (1-12).

[7] Рудяк В.Я., Краснолуцкий С.Л. // ЖТФ. 2017. Т. 87. В. 10. C. $1450-1458$.

[8] Pryazhnikov M.I., Minakov A.V., Rudyak V.Ya., Guzei D.V. // Int. J. Heat Mass Transfer. 2017. V. 104. N 1. P. 1275-1282.

[9] Munyalo J.M., Zhang X. // J. Mol. Liq. 2018. V. 265. P. 77-87.

[10] Einstein A. // Ann. der Phys. 1906. Bd. 19. S. 289-306.

[11] Batchelor G.K. // J. Fluid Mech. 1977. V. 83. Pt 1. P. 97-117.

[12] Maxwell J.C. A treatise on electricity and magnetism. Oxford: Clarendon Press, 1881. 495 p.

[13] Dong M., Shen L.P., Wang H., Wang H.B., Miao J. // J. Nanomaterials. 2013. V. 2013. P. 842963.

[14] Kalpana Sarojini K.G., Manoj S.V., Singh P.K., Predeep T., Das S.K. // Coll. Surf. A. 2013. V. 417. P. 39-46.

[15] Brunauer S., Emmett P.H., Teller E. // J. Am. Chem. Soc. 1938. V. 60. N 2. P. 309-319.
[16] Минаков А.В., Рудяк В.Я., Гузей Д.В., Пряжников М.И., Лобасов А.С. // Инж.-физ. журн. 2015. Т. 88. № 1. С. 148 160.

[17] Rudyak V.Ya., Belkin A.A., Tomilina E.A., Egorov V.V. // Defect Diff. Forum. 2008. V. 273-276. P. 566-571.

[18] Tabuteau H., Oppong F.K., de Bruyn J.R., Coussot P. // Europhys. Lett. 2007. V. 78. N 6. P. 68007. 